\title{
OH(6-2) spectra and rotational temperature measurements at Davis, Antarctica
}

\author{
P. A. Greet ${ }^{1,2}$, W. J. R. French ${ }^{1,2}$, G. B. Burns ${ }^{1}$, P. F. B. Williams ${ }^{1}$, R. P. Lowe ${ }^{3}$, K. Finlayson ${ }^{1}$ \\ ${ }^{1}$ Australian Antarctic Division, Kingston, Tasmania 7050, Australia \\ 2 Institute of Antarctic and Southern Ocean Studies, University of Tasmania, Hobart, Tasmania, 7001, Australia \\ ${ }^{3}$ Institute for Space and Terrestrial Science, University of Western Ontario, London, Canada N6A3K7
}

Received: 4 January 1996 / Revised: 7 July 1997 / Accepted: 8 July 1997

\begin{abstract}
The $\mathrm{OH}(6-2)$ band was monitored during 1990 at Davis, Antarctica $\left(68.6^{\circ} \mathrm{S}, 78.0^{\circ} \mathrm{E}\right)$ using a CzernyTurner scanning spectrometer. Spectra obtained with a $0.15-\mathrm{nm}$ bandwidth and wavelength steps of $0.005 \mathrm{~nm}$ have been recorded in an attempt to isolate auroral features. This has enabled detailed study of weak features in the region $2837.5-855.5 \mathrm{~nm}$. These weak features can contribute to the apparent intensity of Pbranch lines and to the background. Their presence is allowed for in our calculation of rotational temperature, but the $\mathrm{P}_{1}(3)$ line is excluded because of significant contamination. An average temperature of $221 \pm 2 \mathrm{~K}$ is obtained from a selected data set of 104 spectra. The mid-winter average temperature, for the months of May, June and July, is $224 \pm 2 \mathrm{~K}$, which is consistent with the 1986 CIRA model values for mid-winter at this height and latitude, but this result is dependent on the choice of transition probabilities. Preliminary assessments of seasonal and diurnal variations in rotational temperature and intensity are presented.
\end{abstract}

Key words. Atmospheric composition and structure . Airglow and aurora; Middle-atmosphere composition and chemistry - Pressure, density and temperature

\section{Introduction}

Hydroxyl $(\mathrm{OH})$ emissions are used extensively for studies of the upper mesosphere (e.g. Offermann and Gerndt, 1990; Sivjee, 1992). The emission originates from a layer near $87 \mathrm{~km}$ with a mean thickness of $8 \mathrm{~km}$ (Baker and Stair, 1988). The atmospheric emission has a number of bands, and by comparing the intensity of two

Correspondence to: Dr. G. Burns e-mail: gary-bur@antdiv.gov.au or more lines within one branch of a band, the rotational temperature of the molecule can be determined. By assuming that excited $\mathrm{OH}$ molecules are in thermal equilibrium with the atmosphere, this rotational temperature can be interpreted as kinetic atmospheric temperature.

OH-band intensity measurements have been made for various studies, mostly of wave activity in the mesosphere (e.g. Elphinstone et al., 1988; Myrabo and Harang, 1988; Hecht et al., 1987). Wave activity can be seen in both temperature and intensity variations. $\mathrm{OH}$ rotational temperature measurements have been made at a number of northern polar observatories (e.g. Myrabo, 1984, 1986; Offermann et al., 1987; Sivjee and Hamwey, 1987; Lowe et al., 1991). These measurements have been compared to models (Offermann et al., 1987; Offermann and Gerndt, 1990). Taylor et al. (1995) recorded a substantial number of $\mathrm{OH}$ temperatures less than $154 \pm 2 \mathrm{~K}$ on nights when noctilucent clouds were seen above the spectrometer observatory and very few measurements less than this value when no clouds were present. Variations in the distribution of polar mesospheric clouds (Olivero and Thomas, 1986) and polar mesospheric summer echoes (Balsley et al., 1995) suggest significant differences in upper mesosphere/mesopause temperatures between northern and southern polar latitudes.

Observations are available from fewer southernthan northern-hemisphere sites. Recent southern-hemisphere observations have been reviewed by Scheer (1995). Takahashi et al. (1984, 1986) obtained measurements at southern equatorial latitudes; Armstrong (1975, 1982), Scheer and Reisin (1990) and Hobbs et al. (1996) at southern mid-latitudes; and Williams (1996), Sivjee and Walterscheid (1994) and Stubbs et al. (1983) at Antarctic stations. Hobbs et al. (1996) and Williams (1996) used the same instrument as this study, though analysis techniques are different. Stubbs et al. (1983) used a six-channel photometer at Mawson, Antarctica $\left(67.6^{\circ} \mathrm{S}, 62.9^{\circ} \mathrm{E}\right)$, and reported anomalously low temperatures (a mean of $160-170 \mathrm{~K}$ during winter). We 
suspect that this is because of inadequate accounting of auroral contamination of the $(8-3) \mathrm{P}_{1}(2)$ line and an overestimation of the background intensity. Both of these factors would act to lower temperature estimates. Sivjee and Walterscheid (1994) observed the OH(3-1) band to determine tidal oscillations at the South Pole Station.

The primary aim of this experiment is to establish and maintain a long-term record of $\mathrm{OH}$ temperatures from an Antarctic station for climate-change studies. Decreases in temperature and increases in water vapour in the upper-mesosphere/mesopause region are expected to occur with increases in carbon dioxide and methane in the lower atmosphere (Thomas, 1996). Recent observations of noctilucent clouds and the thermal structure of the Arctic mesopause have been made by Lübken et al. (1996). The temperature measurements reported were made with falling spheres and were used to show, in comparison with historical measurements, that the lower edge of noctilucent clouds have formed at the same height $(82 \mathrm{~km})$ and at the same temperature $(150 \pm 2 \mathrm{~K})$ for the last three decades. Other rocket-borne temperature measurements in the mesosphere and lower-thermosphere region have been compared with sodium lidar temperature measurements by Lübken and von Zahn (1989). Ground-based techniques, most suitable for long-term studies, include: Rayleigh lidar in the mesosphere (e.g. Keckhut et al., 1995), sodium lidars in the uppermesosphere/lower-thermosphere region (e.g. Lübken and von Zahn, 1991; Bills et al., 1991), and passive observations of optical emissions in which measurements can be made of either the kinetic temperature using high-resolution Fabry-Perot spectrometers (e.g. Greet, 1997) or the rotational temperature from molecular band structure using a variety of lowerresolution instruments (e.g. Sivjee, 1992). With current technology the simplest and most reliable form of monitoring long-term mesospheric temperature changes from a remote and isolated Antarctic station is with a passive technique. As $\mathrm{OH}$ rotational temperatures have been recorded at Davis for a number of years this technique is being assessed for long-term studies.

For $\mathrm{OH}$ rotational temperature measurements to record long-term temperature trends of several degrees over a number of years, careful calibration and analysis is required to ensure that long-term variation in an instrumental parameter or other small spectral feature is not influencing derived temperatures. In this paper we identify fine detail in the spectra, explore possible sources of uncertainty in the temperature analysis and present initial results from one year's data. The experiment is part of a suite of instruments, including a medium-frequency, spaced-antennae radar, airglow imager and photometers, at Davis, Antarctica $\left(68.6^{\circ} \mathrm{S}, 78.0^{\circ} \mathrm{E}\right)$ which together will be used in comprehensive middle-atmosphere studies (Morris et al., 1995).

\section{Instrumentation}

A Czerny-Turner scanning spectrometer (CZT) has been run for a number of years at Davis. The data presented here were collected in 1990. During this period of operation the spectrometer had a $6^{\circ}$ field of view and the optical axis elevated $30^{\circ}$ above the SE horizon (azimuth $130^{\circ} \mathrm{E}$ ), away from the most aurorally active region of the sky. The $\mathrm{OH}$-emission region monitored is $18 \mathrm{~km}$ in a NE-SW direction by $37 \mathrm{~km}$ in a NW-SE direction, centred at $69.4^{\circ} \mathrm{S}, 80.9^{\circ} \mathrm{E}$.

An instrument bandwidth of $0.15 \mathrm{~nm}$ was achieved with the curved entrance and exit slits opened to $250 \mu \mathrm{m}$ in width and $50 \mathrm{~mm}$ in height. This permitted significant transmission of the $\mathrm{OH}$-emission lines while still providing enough resolution to identify auroral and satellite features. This slit width is inadequate to resolve the $\Lambda$-doubling of $\mathrm{OH}$ lines. A cooled GaAs photomultiplier tube was used for photon detection. The CZT was operated in 1990 without an appropriate higher-order blocking filter.

The instrument response is determined using a quartz-halogen lamp which was measured nine times, five scans on each occasion, during 1990. The lamp has remained with the CZT and was calibrated by reference to a lamp of known spectral irradiance in 1996. To obtain the instrument spectral calibration it is assumed that the 1996 calibration measures the lamp's spectral shape for 1990. Although there are 6 years between instrument and lamp calibration, the lamp has been sparingly used and is operated well below its current rating. A single instrument response is used for the 1990 data.

To characterize the instrument function and the intensity and location of Rowland ghosts from this CZT, a frequency-stabilized laser at $\lambda 632.82 \mathrm{~nm}$ was used to illuminate the optical system. This yielded a triangular instrument function and revealed Rowland ghosts displaced 0.275 and $0.535 \mathrm{~nm}$ from the primary peak. The magnitudes of these ghosts are $0.45 \%$ and $0.13 \%$ of the primary peak, respectively. An Argon doublet, within the $\mathrm{OH}(6-2)$ band, revealed ghosts at 0.335 and $0.695 \mathrm{~nm}$ from the primary peaks. The instrument function may vary between observing campaigns, or from year to year, if the optical alignment is modified.

Spectra were generally accumulations of five sequential scans, with photon counts in each scan made at $0.1-\mathrm{s}$ dwell and 0.005-nm intervals. Each spectrum, which took of the order of an hour to acquire, covers the $\lambda 837.5-\lambda 856.0-\mathrm{nm}$ range. Major emission features of this spectral region are shown in Fig. 1. Approximately half the time is spent stepping the CZT between acquisitions and repositioning for sequential scans. A six-filter photometer (Stubbs et al., 1983) was operated in conjunction with the CZT for part of 1990. The filter photometer sampled the $\mathrm{OH}(6-2) \mathrm{P}_{1}(2)$ line every $150 \mathrm{~s}$. Coincident photometric and CZT observations are useful in determining the effect of long acquisition times on the temperature estimates. 


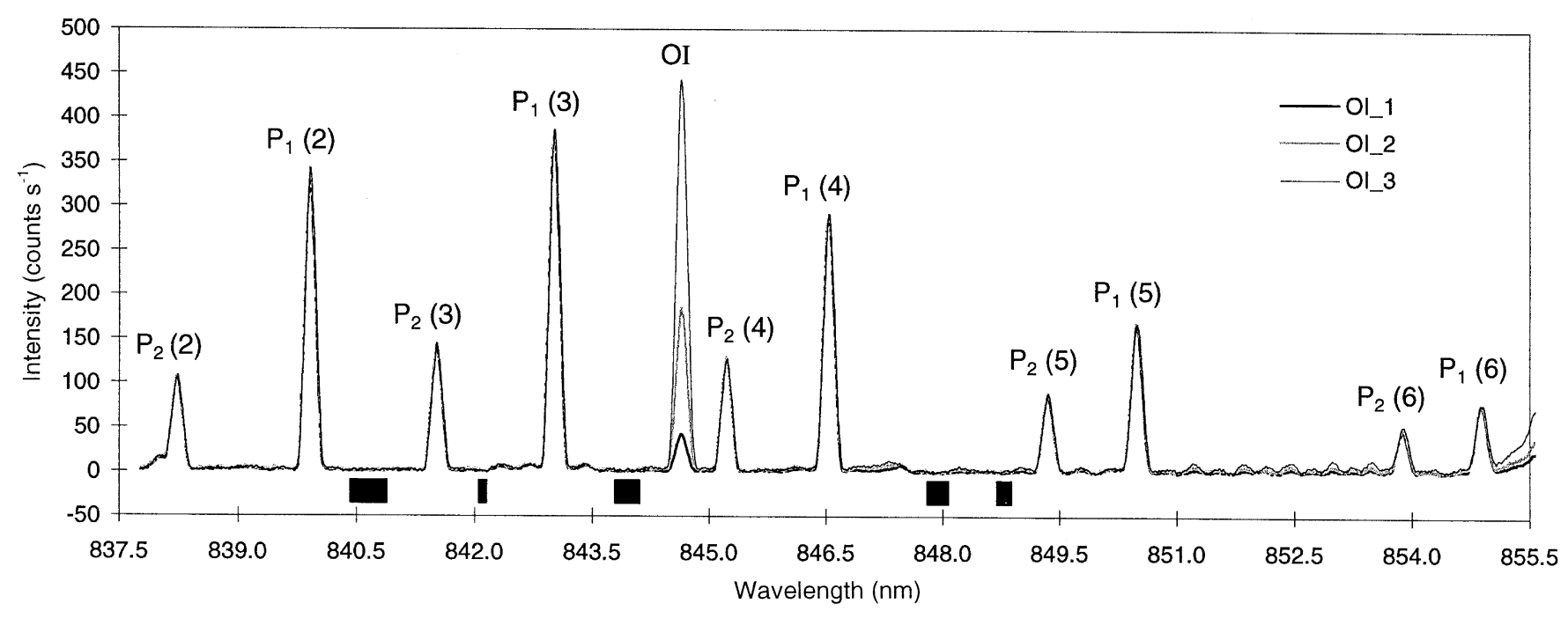

Fig. 1. Averaged and smoothed spectra of the $\mathrm{OH}(6-2)$ band region at three levels of auroral activity. Smoothing was applied with a filter of less than 0.02-nm half-width. Significant features are labelled and

\section{Data}

Data acquisition is limited by day length at Davis. During 1990, data were collected over the interval from day of year (DOY) 90 to DOY 270 (31 March-27 September). This observing period was further split into campaigns centred on new moon periods.

A principal reference data set consists of 104 spectra for which:

clear skies were recorded (visual observation),

the sun was more than $18^{\circ}$ below the horizon,

the moon was below the horizon, and

the aurorally sensitive OI line at $\lambda 844.6 \mathrm{~nm}$ was less intense than the $\mathrm{OH}(6-2) \mathrm{P}_{1}(3)$ emission.

This data set contains the best spectra for the CZT operating mode adopted in 1990. An expanded data set, of 277 spectra, was selected by incorporating criteria chosen near the upper limit of the range of values in the principal data set. The selection criteria for the expanded data set are:

That the sun was more than $18^{\circ}$ below the horizon. That a linear fit across five background regions, identified by the black bands below the spectra in Fig. 1, has a slope of less than 0.6 counts $\mathrm{s}^{-1} \mathrm{~nm}^{-1}$ (This amounts to a maximum difference between $\mathrm{P}_{1}(2)$ and $\mathrm{P}_{1}(5)$ due to a slope in the background of 6 counts $\mathrm{s}^{-1}$ and compares with an average peak signal for $\mathrm{P}_{1}(3)$ in the principal data set of 385 counts $\mathrm{s}^{-1}$ ); this criteria removes extreme moon and variable cloud influences.

That the uncertainty in the temperature estimate due to counting statistics is less than $7 \mathrm{~K}$; this eliminates spectra with significantly reduced intensities due to cloud cover.

That the weighted standard deviation of the temperature, as calculated from different line pair ratios, is less than $10 \mathrm{~K}$. regions investigated for background sampling are shown by black bands below the spectral profile.

That $\mathrm{OI} / \mathrm{P}_{1}(3)<2$; this criteria eliminates extreme auroral influences.

\section{Identification of weak spectral features}

Minor features in the spectra are from three main sources: aurorae, Rowland ghosts (Longhurst, 1957) and minor $\mathrm{OH}$-band emissions. Such features may contaminate the major lines used for rotational temperature measurements and background regions which must be subtracted when determining the intensity of each line. Knowledge of minor features facilitates the selection of appropriate lines and background regions to minimize the spectral region scanned. Also, the instrument function may be optimized by increasing the instrument function width while minimizing contamination from known minor features. The possibility of auroral contamination is very high in Davis spectra. Rejection of all aurorally contaminated spectra, as has been done by others (e.g. Myrabo et al., 1987; Cogger et al., 1988), is not desirable, and thus a study of auroral detail is necessary.

Table 1 gives wavelengths and $\Lambda$-doubling for the major $\mathrm{P}_{1}$ lines in the $\mathrm{OH}(6-2)$ spectra and nearby minor features, calculated from term energies given by Coxon (1980) and Coxon and Foster (1982).

The last two columns in Table 1 compare measured intensities for the main and satellite lines with those calculated for a rotational temperature of $221 \mathrm{~K}$. The transition probabilities of Turnbull and Lowe (1989) were used in calculating the intensities of the main branch lines. Goldman (1982) gives approximate transition probabilities for satellite lines relative to the Mies (1974) values for the main branch transitions. In estimating the transition probabilities for the satellite lines consistent with the Turnbull and Lowe values, it was assumed that the ratio of the satellite line to the 
Table 1(a),(b). Wavenumbers, wavelengths, $\Lambda$-doubling and intensities compared with observed wavelengths and intensities for the principal data set from (a) main branch lines and (b) proposed identifications of minor non-aurorally dependent spectral features near the main branch lines. All lines are from the $\mathrm{OH}(6-2)$ band except those marked by $\dagger$ which are from the $\mathrm{OH}(5-1)$ band as identified by Osterbrock et al. (1997).

\begin{tabular}{llllllll}
\hline line & $v_{\text {vac }}$ & $\lambda_{\text {air }}$ & $\Delta \lambda_{\Lambda}$ & $\lambda_{\text {mean }}$ & $\lambda_{\text {obs }}$ & & $\mathrm{I}(221 \mathrm{~K})$ \\
\cline { 4 - 6 } & $\left(\mathrm{cm}^{-1}\right)$ & $(\mathrm{nm})$ & $(\mathrm{nm})$ & $(\mathrm{nm})$ & $(\mathrm{nm})$ & theory & observed \\
\hline
\end{tabular}

(a) $\mathrm{OH}(6-2)$ main branch lines

$\begin{array}{rrrrrrrr}\mathrm{P}_{1}(2) \mathrm{f} & 11902.6 & 839.921 & 0.0101 & 839.916 & 839.92 & 85.7 & \text { scaled to } 85.7 \\ \mathrm{e} & 11902.8 & 839.910 & & & & 100.6 \\ \mathrm{P}_{1}(3) \mathrm{f} & 11858.8 & 843.026 & 0.0190 & 843.017 & \text { aligned } & 100.0 & 0.2 \\ \mathrm{e} & 11859.0 & 843.007 & & & & 76.7 & 77.2 \pm 0.1 \\ \mathrm{P}_{1}(4) \mathrm{f} & 11809.4 & 846.550 & 0.0305 & 846.535 & 846.54 & & 44.7 \pm 0.1 \\ \mathrm{e} & 11809.8 & 846.519 & & & & \\ \mathrm{P}_{1}(5) \mathrm{f} & 11754.5 & 850.505 & 0.0431 & 850.484 & 850.48 & & \end{array}$

(b) Weak features of interest

\begin{tabular}{|c|c|c|c|c|c|c|c|}
\hline $\mathrm{Q}_{1}(4) \mathrm{e}$ & 11928.9 & 838.073 & 0.083 & 838.032 & & 6.1 & $4.9 \pm 0.3$ \\
\hline $\mathrm{f}$ & 11930.0 & 837.990 & & & & & \\
\hline $\mathrm{Q}_{1}(5) \mathrm{e}$ & 11901.3 & 840.017 & 0.104 & 839.964 & blended & 1.8 & blended \\
\hline $\mathrm{f}$ & 11902.7 & 839.912 & & & with $\mathrm{P}_{1}(2)$ & & with $\mathrm{P}_{1}(2)$ \\
\hline$Q_{1}(6) e$ & 11867.3 & 842.417 & 0.192 & 842.322 & 842.33 & 0.5 & $2.4 \pm 0.6$ \\
\hline $\mathrm{f}$ & 11870.0 & 842.226 & & & & & \\
\hline$\dagger \mathrm{P}_{2}(12) \mathrm{f}$ & 11864.2 & 842.639 & 0.094 & 842.686 & ) & & ) \\
\hline $\mathrm{e}$ & 11862.9 & 842.733 & & & ) & & ) \\
\hline${ }^{Q} \mathrm{R}_{12}(2) \mathrm{e}$ & 11862.8 & 842.743 & 0.008 & 842.747 & ) & 0.5 & ) \\
\hline $\mathrm{f}$ & 11862.6 & 842.751 & & & 842.71 & & $1.3 \pm 0.3$ \\
\hline${ }^{Q} \mathrm{R}_{12}(3) \mathrm{e}$ & 11862.4 & 842.771 & 0.001 & 842.771 & ) & 0.1 & ) \\
\hline $\mathrm{f}$ & 11862.4 & 842.771 & & & ) & & ) \\
\hline$\dagger \mathrm{P}_{1}(12) \mathrm{e}$ & 11858.2 & 843.070 & 0.147 & 843.144 & blended & & blended \\
\hline $\mathrm{f}$ & 11856.1 & 843.217 & & & with $P_{1}(3)$ & & with $P_{1}(3)$ \\
\hline${ }^{Q} \mathrm{R}_{12}(1) \mathrm{e}$ & 11853.1 & 843.433 & 0.008 & 843.437 & 843.43 & 1.2 & $1.7 \pm 0.3$ \\
\hline $\mathrm{f}$ & 11852.9 & 843.441 & & & & & \\
\hline${ }^{P} \mathrm{Q}_{12}(2) \mathrm{e}$ & 11796.9 & 847.451 & 0.019 & 847.460 & 847.44 & 1.5 & $2.0 \pm 0.3$ \\
\hline $\mathrm{f}$ & 11796.6 & 847.470 & & & & & \\
\hline$\dagger \mathrm{P}_{1}(13) \mathrm{e}$ & 11760.3 & 850.086 & 0.167 & 850.179 & blended with & & blended with \\
\hline $\mathrm{f}$ & 11758.0 & 850.253 & & & $P_{1}(5)$ ghost & & $P_{1}(5)$ ghost \\
\hline
\end{tabular}

main branch transition with the same upper state remained constant at the value given by Goldman.

A selection of spectra from the expanded data set were grouped into three sets based on the intensity of the aurorally sensitive OI $(2844.6 \mathrm{~nm})$ emission. The spectra in these three sets were averaged, using the $\mathrm{P}_{1}(3)$ line to align each spectrum, and smoothed. The smoothing is only included to make small features more easily visible in the figures. The smoothing has a minor effect on widths and relative magnitudes of lines. Temperature analysis and relative scaling of features is performed only on unsmoothed data. Each of the smoothed, averaged spectra have been scaled to give a $\mathrm{P}_{1}(3)$ count rate equivalent to an averaged principal spectrum $\left(385\right.$ counts s$\left.{ }^{-1}\right)$. Figure 2 shows spectral regions in the vicinity of the $\mathrm{P}_{1}(2), \mathrm{P}_{1}(3), \mathrm{P}_{1}(4)$ and $\mathrm{P}_{1}(5)$ lines in expanded form. Major lines in the region have been truncated at 16 counts $\mathrm{s}^{-1}$, approximately $4 \%$ of the maximum intensity of the major $\mathrm{P}_{1}$ branch lines which are labelled for clarity.

Aurorally sensitive background features are apparent in Fig. 2. The major auroral features which directly influence the $\mathrm{OH}(6-2)$ region are the $\mathrm{N}_{2}^{+}$Meinel (4-2) $[2827-878 \mathrm{~nm}]$ band and the $\mathrm{N}_{2}$ 1PG(3-2)
[2818-861 nm] band (Hecht et al., 1987; Viereck and Deehr, 1989). Second-order lines from the auroral $\mathrm{N}_{2}^{+} 1 \mathrm{NG}(1-2)[\lambda 419-424 \mathrm{~nm}]$ and $\mathrm{N}_{2}^{+} 1 \mathrm{NG}(0-1)[\lambda 422-$ $428 \mathrm{~nm}]$ bands are also present.

$\mathrm{P}_{1}(2)$ shows no evidence of contamination. Small features $\pm 0.3 \mathrm{~nm}$ from the line are consistent with Rowland ghosts. Examination of a theoretical $\mathrm{OH}(6-2)$ spectrum shows that the $\mathrm{Q}_{1}(5)$ line, at $2839.964 \mathrm{~nm}$ ( $\Lambda$-doubling of $0.104 \mathrm{~nm}$ ), is coincident with the $\mathrm{P}_{1}(2)$ line.

$P_{1}(3)$ shows three nearby features which are not aurorally sensitive and which are too strong to be solely due to ghosts. Originally, these were assigned to the $\mathrm{OH}(6-2)$ band features: $\mathrm{Q}_{1}(6)$, and the satellite lines ${ }^{Q} \mathbf{R}_{12}(2),{ }^{Q} \mathbf{R}_{12}(3)$ and ${ }^{Q} \mathbf{R}_{12}(1)$. The lines ${ }^{Q} \mathbf{R}_{12}(2)$ and $Q_{\mathbf{R}_{12}}$ (3) are not resolvable with our instrument. Temperature analysis also indicated that a further minor emission existed under the $\mathrm{P}_{1}(3)$ line. Subsequently, Osterbrock et al. (1997) proposed high-order OH(5-1) features in this region: $\mathrm{OH}(5-1) \mathrm{P}_{2}(12)[2842.7 \mathrm{~nm}]$ and $\mathrm{OH}(5-1) \mathrm{P}_{1}(12)[\lambda 843.20 \mathrm{~nm}]$. Some of these minor $\mathrm{OH}$ features are significantly broadened by $\Lambda$-doubling (see Table 1). The shape of the overlapped $\mathrm{OH}(6-2){ }^{Q} \mathrm{R}_{12}(2$ and 3) and $\mathrm{OH}(5-1) \mathrm{P}_{2}(12)$ features and the $\mathrm{OH}(6-2)$ 

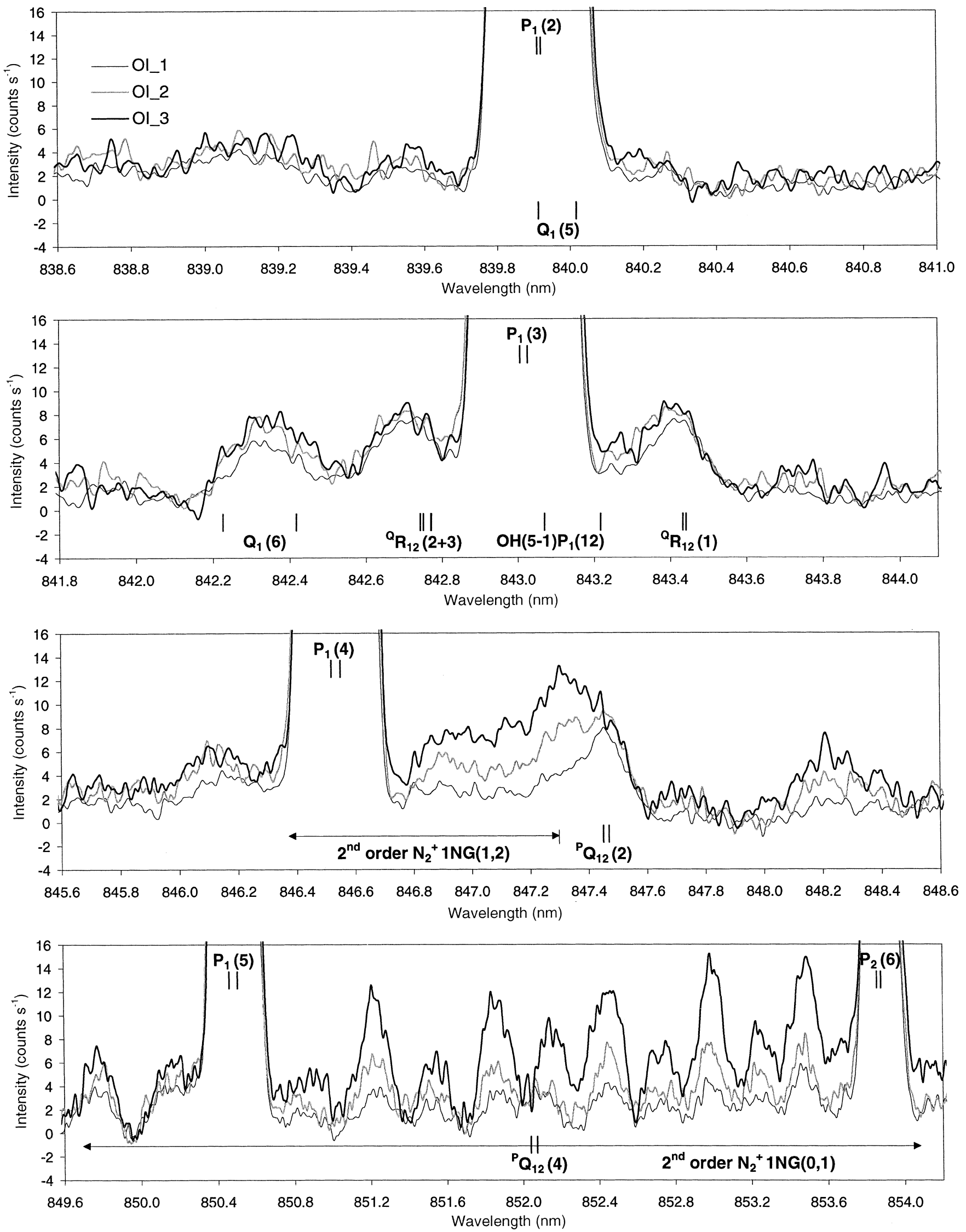

Fig. 2. Averaged and smoothed spectra, at three levels of auroral activity, showing the auroral dependence of weak spectral features in the vicinity of the $\mathrm{P}_{1}(2), \mathrm{P}_{1}(3), \mathrm{P}_{1}(4)$ and $\mathrm{P}_{1}(5)$ lines of the $\mathrm{OH}(6-2)$ band. The main $\mathrm{P}$ branch features, their intensity truncated at 16 counts $\mathrm{s}^{-1}$, are labelled. Identification of weak spectral features is made below the spectral profiles. 
$Q_{\mathbf{R}_{12}}(1)$ feature are distorted by a superposed Rowland ghost from the $\mathrm{P}_{1}(3)$ line. Since the $\mathrm{P}_{1}(12)$ lines are unthermalized and the $\mathrm{OH}(5-1)$ intensity is unknown, a correction to the $\mathrm{P}_{1}(3)$ line is impossible, and therefore the $\mathrm{P}_{1}(3)$ line is not used for rotational temperature analysis.

$\mathrm{P}_{1}(4)$ has a small auroral contribution, principally from the $\mathrm{N}_{2}$ 1PG(3-2) band, superimposed on the Rowland ghosts. The ${ }^{P} \mathrm{Q}_{12}(2)$ satellite emission is apparent approximately $+1.0 \mathrm{~nm}$ from the $\mathrm{P}_{1}(4)$ line; see Fig. 2. As auroral activity increases, a broader feature with a band head near the ${ }^{P} \mathrm{Q}_{12}(2)$ emission becomes apparent. This is principally due to second-order transmission of $\mathrm{N}_{2}^{+} 1 \mathrm{NG}(1-2)$ band [ $\left.2419-424 \mathrm{~nm}\right]$.

$\mathrm{P}_{1}(5)$ has an aurorally dependent, combined second order $\mathrm{N}_{2}^{+} 1 \mathrm{NG}(0-1)[\lambda 422-428 \mathrm{~nm}]$, and first-order $\mathrm{N}_{2}$ $1 \mathrm{PG}(3-2)$ feature under it. The aurorally sensitive sequence of alternating large and small background peaks, most readily apparent at wavelengths higher than the $\mathrm{P}_{1}(5)$ line, are principally due to second-order $\mathrm{N}_{2}^{+}$ $1 \mathrm{NG}(0-1)$. A minor feature $1.6 \mathrm{~nm}$ from $\mathrm{P}_{1}(5)$ is probably the ${ }^{P} \mathrm{Q}_{12}(4)$ line at $\lambda 852.06 \mathrm{~nm}$. The $\mathrm{OH}(5-1)$ $\mathrm{P}_{1}$ (13) line would potentially be a problem if the instrument function were wider than its current value of $0.15 \mathrm{~nm}$.

None of the lines listed in Table 1 suffers significantly from atmospheric absorption. The only absorber of consequence in the wavelength range covered is $\mathrm{H}_{2} \mathrm{O}$. A maximum concentration of $10-\mathrm{mm}$ precipitable water is estimated for the Antarctic coastal site of Davis. Using high-resolution telluric absorption spectra (HITRAN92; Rothman et al., 1992) and the technique described in Turnbull and Lowe (1983), the lowest transmission calculated for the $\mathrm{P}_{1}(k)$ lambda components listed is $99.98 \%$. The lowest transmission for the $Q_{1}(k)$ lines is $99.9 \%$, and for the satellite lines is $98.8 \%$.

\section{Rotational temperature analysis}

Rotational temperatures are calculated from ratios of any two of the measured $\mathrm{P}_{1}$-branch lines corrected for instrument response (Meriwether, 1985). The accuracy of temperatures derived from individual ratios is determined, taking into account relative line intensities, the sensitivity of each particular ratio to temperatures in the emission region, uncertainties in background esti- mates and contamination by minor emissions. Average temperatures and estimated uncertainties are derived for each of the six possible ratios. This approach is adopted to quantify the accuracy possible from individual line ratios and to determine if significant contamination of line intensities remains. If a line intensity is significantly mis-estimated, average temperatures derived from that ratio will be systematically different from temperatures derived from other ratios. For the Davis 1990 data this enables estimation of the average contribution of the unthermalized $\mathrm{OH}(5-1) \mathrm{P}_{1}(12)$ emission to the measured $\mathrm{P}_{1}(3)$ intensity.

Temperatures are also calculated for each spectrum. These are weighted averages of the temperatures derived from the $\mathrm{P}_{1}(2) / \mathrm{P}_{1}(4), \mathrm{P}_{1}(2) / \mathrm{P}_{1}(5)$ and $\mathrm{P}_{1}(4) / \mathrm{P}_{1}(5)$ ratios, described henceforth as the weighted temperature. This section discusses the effect of aurora, the $\mathrm{Q}_{1}(5)$ line, $\Lambda$-doubling and transition probabilities on temperature calculations, and how these effects may be allowed for. Values given in the following discussion and listed in Table 2 are for the principal data set.

Auroral contamination was estimated from theoretical spectra programs provided by Gattinger (personal communication). Theoretical spectra of the $\mathrm{N}_{2}^{+}$Meinel bands (principally 4-2), $\mathrm{N}_{2} 1 \mathrm{PG}$ (principally 3-2) and $\mathrm{N}_{2}^{+} 1 \mathrm{NG}(0-1$ and 1-2) were calculated for a range of emission temperatures, convolved with an instrument response function, summed and fitted to the most 'aurorally active' average spectrum. A temperature of $500 \mathrm{~K}$ for the auroral $\mathrm{N}_{2}$ emission region gave the best fit. A comparison of theoretical and measured auroral contributions in the vicinity of the major lines is shown in Fig. 3.

The combined theoretical auroral spectrum was used to relate the sum under three $\mathrm{N}_{2}$ auroral features, at $\lambda 851.9, \lambda 852.4$ and $\lambda 853.0 \mathrm{~nm}$, to auroral contributions under the major $\mathrm{P}_{1}$-branch lines. The sum of these three auroral features in each spectrum is used to calculate an auroral contribution, $a_{k}$, to subtract from the $\mathrm{OH}(6-2)$ intensity measurements, $\mathrm{P}_{1}(k)$. In Table 2, column $\mathrm{A}$, the average auroral corrections for the individual ratios are listed. Allowing for auroral corrections reduces the average temperature by $2 \mathrm{~K}$. Use of an appropriate order separating filter would obviate the need to allow for $\mathrm{N}_{2}^{+} 1 \mathrm{NG}$ contamination. The estimated corrections for direct $\mathrm{N}_{2}^{+} \quad 1 \mathrm{PG}$ and $\mathrm{N}_{2}^{+}$Meinel band auroral contamination, scaled to an $\mathrm{OI} / \mathrm{P}_{1}(3)$ ratio of 1.0 , are

Table 2. Temperature corrections for individual ratios and the 'weighted' temperature correction (see text) for the principal data set from: (A) total auroral correction for principal data set; (B) auroral corrections for first-order contaminations, scaled to OI/ $\mathrm{P}_{1}(3)=1.0 ;(\mathrm{C})$ $\Lambda$-doubling; (D) $\mathrm{Q}_{1}(5)$ under $\mathrm{P}_{1}(2)$; (E) Mies (1974) transition probabilities; (F) Langhoff et al. (1986) transition probabilities.

\begin{tabular}{lcccccc}
\hline ratio & $\mathrm{A}$ & $\mathrm{B}$ & $\mathrm{C}$ & $\mathrm{D}$ & $\mathrm{E}$ & $\mathrm{F}$ \\
\hline $\mathrm{P}(2) / P 1(3)$ & $-1 \mathrm{~K}$ & $-1 \mathrm{~K}$ & $+2 \mathrm{~K}$ & $+9 \mathrm{~K}$ & $-11 \mathrm{~K}$ & $-19 \mathrm{~K}$ \\
$\mathrm{P}_{1}(2) / \mathrm{P}_{1}(4)$ & $-1 \mathrm{~K}$ & $-2 \mathrm{~K}$ & $+2 \mathrm{~K}$ & $+4 \mathrm{~K}$ & $-8 \mathrm{~K}$ & $-14 \mathrm{~K}$ \\
$\mathrm{P}_{1}(2) / \mathrm{P}_{1}(5)$ & $-3 \mathrm{~K}$ & $-4 \mathrm{~K}$ & $+2 \mathrm{~K}$ & $+2 \mathrm{~K}$ & $-7 \mathrm{~K}$ & $-12 \mathrm{~K}$ \\
$\mathrm{P}_{1}(3) / \mathrm{P}_{1}(4)$ & $-1 \mathrm{~K}$ & $-2 \mathrm{~K}$ & $+2 \mathrm{~K}$ & & $-6 \mathrm{~K}$ & $-11 \mathrm{~K}$ \\
$\mathrm{P}_{1}(3) / \mathrm{P}_{1}(5)$ & $-3 \mathrm{~K}$ & $-4 \mathrm{~K}$ & $+3 \mathrm{~K}$ & & $-6 \mathrm{~K}$ & $-10 \mathrm{~K}$ \\
$\mathrm{P}_{1}(4) / \mathrm{P}_{1}(5)$ & $-5 \mathrm{~K}$ & $-6 \mathrm{~K}$ & $+3 \mathrm{~K}$ & & $-5 \mathrm{~K}$ & $-9 \mathrm{~K}$ \\
wtd. average & $-2 \mathrm{~K}$ & $-3 \mathrm{~K}$ & $+2 \mathrm{~K}$ & $+2 \mathrm{~K}$ & $-7 \mathrm{~K}$ & $-12 \mathrm{~K}$ \\
\hline
\end{tabular}



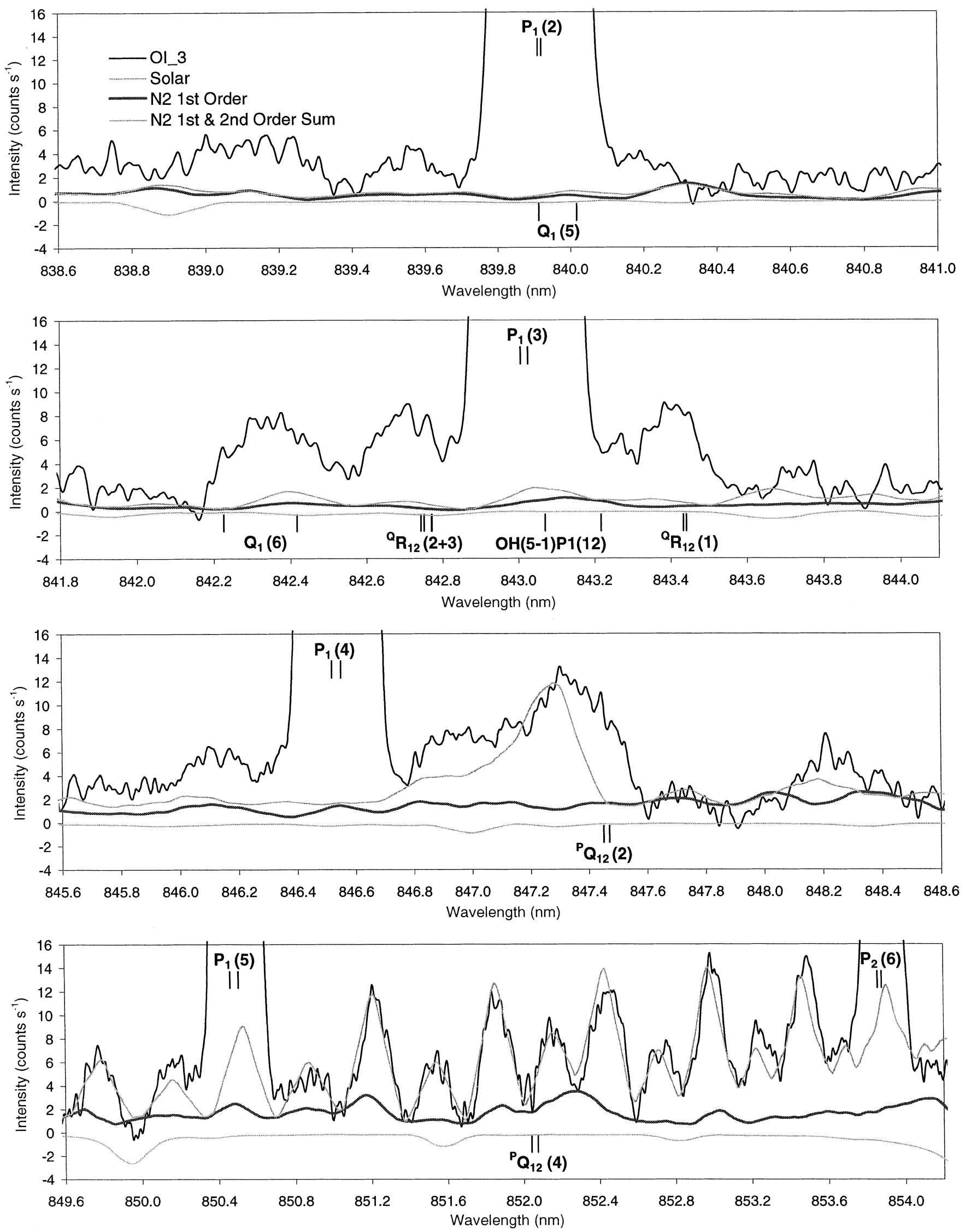

Fig. 3. The most aurorally active spectrum from Fig. 2, for which $\mathrm{OI} / \mathrm{P}_{1}(3)$ average $=1.15$, and showing theoretical first and secondorder $\mathrm{N}_{2}$ band auroral contamination fitted to the data and the theoretical auroral contamination for first order only. A solar Fraunhofer spectrum, arbitrarily scaled to fit the data, is shown below the zero line. This contamination is from scattered moonlight. 
listed in column B of Table 2. The principal data set has an average $\mathrm{OI} / \mathrm{P}_{1}(3)$ ratio of 0.28 . The auroral intensity of the OI line is only weakly correlated with the $\mathrm{N}_{2}$ auroral emissions, but it is the most intense aurorally influenced feature in the $\mathrm{OH}(6-2)$ spectral range.

The five background regions marked in Fig.1 all have minor contaminations. The background for each line was estimated as a fraction of nearby background regions. The fractions were chosen by examination of the average of the principal spectra. The uncertainty in the background for all lines in an individual spectrum, $e_{b}$, is estimated to be $\sigma / \sqrt{n}$, where $\sigma$ is the standard deviation of the $n$ sample points in the background region $2840.43-840.88 \mathrm{~nm}$ (the lowest wavelength background region in Fig. 1).

The emission line intensity was determined by summing counts over $N$ wavelength increments centred on the $\mathrm{P}_{1}$-branch line, and subtracting a background, $b_{k}$, (which includes a contribution of photomultiplier dark counts) and an estimated auroral contribution, $a_{k}$. The uncertainty in the auroral correction was estimated as half the auroral contamination of each line. Increasing the number of wavelength increments summed changes the relative error in the intensity measurements, which is calculated as

$R E(k)=\frac{\sqrt{\sum_{i=1}^{N} C_{i}+\left(N e_{b}\right)^{2}+0.25 a_{k}^{2}}}{\sum_{i=1}^{N}\left(C_{i}-b_{k}\right)-a_{k}}$.

$C_{i}$ is the total number of counts at sample $i$. The value of $N$ for which the relative error is minimized varies for each line in the spectrum, but for our data 51 $(=0.25 \mathrm{~nm})$ is a reasonable value. To make an accurate temperature estimate, each component of the $\Lambda$-doubled lines has to be summed over the same width. Because $\Lambda$-doubling is not resolved in our spectra, we chose to sum over a fixed width of $0.25 \mathrm{~nm}$ for all lines and allow for $\Lambda$-doubling using a factor calculated assuming a triangular instrument function of $0.15 \mathrm{~nm}$ fwhm. The $\Lambda$-doubling corrections for each ratio are listed in Table 2 , column $C$. If $\Lambda$-doubling were not accounted for in the analysis, measured temperatures would decrease by $2 \mathrm{~K}$.

The percentage contribution of $\mathrm{Q}_{1}(5)$ to $\mathrm{P}_{1}(2)$ varies with temperature. Theoretically, assuming that the $\mathrm{Q}_{1}(5)$ line is thermalized, the ratio of the $\mathrm{Q}_{1}(5)$ intensity to the $\mathrm{P}_{1}(2)$ intensity amounts to $0.6 \%$ at $150 \mathrm{~K}, 1.7 \%$ at $200 \mathrm{~K}$ and $3.1 \%$ at $250 \mathrm{~K}$. Pendleton et al. (1993) shows that the upper state of $\mathrm{Q}_{1}(5)$ has a small nonthermal component. The deviation from thermalization would not exceed $10 \%$. This would make less than a 1$\mathrm{K}$ temperature variation. When using the $\mathrm{P}_{1}(2)$ line to calculate rotational temperature, we allow for contamination by $\mathrm{Q}_{1}(5)$. The magnitude of $\mathrm{Q}_{1}(5)$ with respect to $\mathrm{P}_{1}(2)$ is calculated by iteration of the weighted temperature. Allowing for the $\mathrm{Q}_{1}(5)$ contribution altered the temperatures of the ratios by the amount shown in Table 2 , column D. The weighted temperatures increased by an average of $2 \mathrm{~K}$.

Columns $\mathrm{E}$ and $\mathrm{F}$ show how temperatures would have differed had the transition probabilities of Mies (1974) and Langhoff et al. (1986) been used.

\section{Results}

The mean temperature for each of the ratios for the principal data set (104 spectra) is listed in Table 3, column A. The average weighted temperature is $221 \mathrm{~K}$. Mean temperatures for individual ratios range from 218 to $231 \mathrm{~K}$ with the mean temperature for $\mathrm{P}_{1}(2) / \mathrm{P}_{1}(3)$ being some $8 \mathrm{~K}$ higher than for any other ratio. The standard deviation of the weighted temperatures is $10 \mathrm{~K}$ and the standard error is $1 \mathrm{~K}$. The standard deviation and standard error for each of the ratios are listed in Table 3, columns B and C.

A relative 'counting' error for each ratio in each spectrum is calculated, $\sqrt{R E(k)^{2}+R E(l)^{2}}$. The average relative counting error for each ratio, converted to a temperature error, is listed in Table 3 , column $\mathrm{D}$. The weighting factors for the contribution of $\mathrm{P}_{1}(2) / \mathrm{P}_{1}(4)$, $\mathrm{P}_{1}(2) / \mathrm{P}_{1}(5)$ and $\mathrm{P}_{1}(4) / \mathrm{P}_{1}(5)$ temperatures to the weighted temperature are calculated inversely as the square of these temperature errors, determined separately for each spectrum. Average weighting factors are $0.32,0.57$ and 0.12 , respectively. The average counting error for the temperatures of the principal spectra is $4 \mathrm{~K}$. Errors calculated in this manner are lower limits for the error of each ratio. There is at least that degree of uncertainty inherent in the photons counted, the background estimate and possible auroral contamination.

Table 3. Average temperatures and uncertainty estimates for individual ratios and the weighted temperature (see text) for the principal data set. (A) average temperatures; (B) standard deviation; (C) standard error in mean; (D) average 'counting error' for individual spectra; (E) standard deviation of 'sampling errors'; (F) mean 'sampling error'; $(\mathrm{G})$ instrument correction uncertainty; $(\mathrm{H})$ average error in individual spectra; (I) estimated error in the average temperatures.

\begin{tabular}{lcccrrrrrr}
\hline & $\mathrm{A}$ & $\mathrm{B}$ & $\mathrm{C}$ & $\mathrm{D}$ & $\mathrm{E}$ & $\mathrm{F}$ & $\mathrm{G}$ & $\mathrm{H}$ & $\mathrm{I}$ \\
\hline $\mathrm{P}_{1}(2) / \mathrm{P}_{1}(3)$ & $231 \mathrm{~K}$ & $18 \mathrm{~K}$ & $2 \mathrm{~K}$ & $13 \mathrm{~K}$ & $11 \mathrm{~K}$ & $-1 \mathrm{~K}$ & $3 \mathrm{~K}$ & $17 \mathrm{~K}$ & $4 \mathrm{~K}$ \\
$\mathrm{P}_{1}(2) / \mathrm{P}_{1}(4)$ & $223 \mathrm{~K}$ & $11 \mathrm{~K}$ & $1 \mathrm{~K}$ & $5 \mathrm{~K}$ & $8 \mathrm{~K}$ & $-1 \mathrm{~K}$ & $2 \mathrm{~K}$ & $10 \mathrm{~K}$ & $2 \mathrm{~K}$ \\
$\mathrm{P}_{1}(2) / \mathrm{P}_{1}(5)$ & $221 \mathrm{~K}$ & $10 \mathrm{~K}$ & $1 \mathrm{~K}$ & $4 \mathrm{~K}$ & $6 \mathrm{~K}$ & $-1 \mathrm{~K}$ & $1 \mathrm{~K}$ & $8 \mathrm{~K}$ & $2 \mathrm{~K}$ \\
$\mathrm{P}_{1}(3) / \mathrm{P}_{1}(4)$ & $218 \mathrm{~K}$ & $11 \mathrm{~K}$ & $1 \mathrm{~K}$ & $8 \mathrm{~K}$ & $9 \mathrm{~K}$ & $-1 \mathrm{~K}$ & $1 \mathrm{~K}$ & $12 \mathrm{~K}$ & $2 \mathrm{~K}$ \\
$\mathrm{P}_{1}(3) / \mathrm{P}_{1}(5)$ & $218 \mathrm{~K}$ & $10 \mathrm{~K}$ & $1 \mathrm{~K}$ & $5 \mathrm{~K}$ & $7 \mathrm{~K}$ & $-1 \mathrm{~K}$ & $1 \mathrm{~K}$ & $9 \mathrm{~K}$ & $2 \mathrm{~K}$ \\
$\mathrm{P}_{1}(4) / \mathrm{P}_{1}(5)$ & $219 \mathrm{~K}$ & $12 \mathrm{~K}$ & $1 \mathrm{~K}$ & $10 \mathrm{~K}$ & $9 \mathrm{~K}$ & $-1 \mathrm{~K}$ & $1 \mathrm{~K}$ & $13 \mathrm{~K}$ & $3 \mathrm{~K}$ \\
wtd. temp. & $221 \mathrm{~K}$ & $10 \mathrm{~K}$ & $1 \mathrm{~K}$ & $4 \mathrm{~K}$ & $7 \mathrm{~K}$ & $-1 \mathrm{~K}$ & $2 \mathrm{~K}$ & $8 \mathrm{~K}$ & $2 \mathrm{~K}$ \\
\hline
\end{tabular}


'Counting' errors do not include any estimate for variation in the intensity or temperature of the emitting region during the acquisition time of almost $1 \mathrm{~h}$.

Coincident CZT and photometric $\mathrm{P}_{1}(2)$ observations existed for 131 spectra of the expanded data set. Assuming that the emitting region temperature was constant $(220 \mathrm{~K})$, a variation in the photometer measured $\mathrm{P}_{1}(2)$ intensity at the time the CZT scanned the major lines can be converted to an equivalent temperature error in the appropriate ratios. The standard deviation of the temperature errors for each ratio is listed in Table 3, column E. By this method, an average error of $7 \mathrm{~K}$ can be associated with the time taken to acquire the spectra collected at Davis in 1990. The mean temperature difference for the 131 spectra is only $-1 \mathrm{~K}$. The average difference, or mean 'sampling error', for each of the ratios, estimated as equivalent to that for the 131 spectra, is listed in Table 3, column F.

It has been reported that the $\mathrm{OH}$ intensity decreases after sunset, although this effect varies between the southern and northern hemisphere (Lowe et al., 1996). It is thought to be at least partially linked to tidal variations, in which case significant latitudinal variation would be expected. The average temperature difference for those spectra recorded prior to local midnight was $-1.3 \mathrm{~K}$, and for those after local midnight was $-0.4 \mathrm{~K}$.

The same instrument correction is applied to all spectra. An uncertainty in this correction is calculated from the variability in the calibration scans used in determining the correction. These are listed in Table 3, column G. An uncertainty of $2 \mathrm{~K}$ is associated with the instrument calibration.

The average error for individual spectra is estimated as the square root of the sum of the squares of the independent error estimates: 'counting' errors (Table 3, column D), 'sampling' errors (Table 3, column E) and the uncertainty in the instrument correction (Table 3, column G). Uncertainties in the auroral corrections are insignificant for individual spectra. The average error for individual spectra amounts to $8 \mathrm{~K}$ for the weighted temperature and is listed for all ratios in Table 3 , column $\mathrm{H}$.

The uncertainty in the average temperatures is estimated as the square root of the sum of the squares of: the standard error in the mean of the temperatures derived from the spectra (Table 2, column C), the uncertainty in the instrument correction (Table 3, col- umn $\mathrm{G}$ ), the mean error in the time taken to acquire a spectrum (Table 3, column F) and an estimated auroral correction uncertainty (= half the average correction; Table 2, column D). For the average of the weighted temperatures this amounts to $2 \mathrm{~K}$, and is listed for all ratios in Table 3, column I.

The average temperatures of the individual ratios (Table 3, column A) provide confirmation that $\mathrm{P}_{1}(3)$ is overestimated. The $\mathrm{P}_{1}(2) / \mathrm{P}_{1}(3)$ average temperature is significantly high. The average $\mathrm{P}_{1}(3) / \mathrm{P}_{1}(4)$ and $\mathrm{P}_{1}(3) / \mathrm{P}_{1}(5)$ temperatures are low, but not significantly so. A comparison of the average $P_{1}(2) / P_{1}(3)$ temperature with the independently derived average weighted temperature is consistent with a minor emission feature, believed to be $\mathrm{OH}(5-1) \mathrm{P}_{1}(12)$ (Osterbrock et al., 1997), of magnitude $1.8 \%$ under the $\mathrm{P}_{1}(3)$ line. The discrepancy in the $P_{1}(2) / P_{1}(3)$ ratio mean temperature is not consistent with non-thermalization of the $\mathrm{Q}_{1}(5)$ emission, blended with $\mathrm{P}_{1}(2)$. Non-thermalization of the $\mathrm{Q}_{1}(5)$ emission would result in a lower average temperature for the $\mathrm{P}_{1}(2) / \mathrm{P}_{1}(3)$ ratio. Similarly, non-thermalization of $\mathrm{Q}_{1}(5)$ would imply a low $\mathrm{P}_{1}(2) / \mathrm{P}_{1}(4)$ mean temperature. This is not supported by the results. This is consistent with the observation that $\mathrm{Q}_{1}(4)$ is thermalized to the limit of the intensity uncertainty of these spectra.

Mean temperatures derived from ratios that include the $\mathrm{P}_{1}(5)$ line provide no evidence for non-thermalization of this line. Non-thermalization of $\mathrm{P}_{1}(5)$ would be reflected in high average temperatures for ratios involving this line. This confirms the results of Pendleton et al. (1993).

The maximum weighted counting error for the principal data set (104 spectra) is $7 \mathrm{~K}$. The maximum weighted standard deviation (a weighted comparison of the $\mathrm{P}_{1}(2) / \mathrm{P}_{1}(4), \mathrm{P}_{1}(2) / \mathrm{P}_{1}(5)$ and $\mathrm{P}_{1}(4) / \mathrm{P}_{1}(5)$ ratios to the weighted temperature) is $10 \mathrm{~K}$. The expanded data set, 277 spectra, excludes spectra for which these values exceeded 7 and $10 \mathrm{~K}$, respectively, and relaxes the auroral limitation criteria to $\mathrm{OI} / \mathrm{P}_{1}(3)<2.0$. Temperatures and uncertainties are listed in Table 4 . The average weighted temperature is $221 \mathrm{~K}$. The average $\mathrm{OI} / \mathrm{P}_{1}(3)$ ratio is 0.49 . Comparing the average temperature of the $\mathrm{P}_{1}(2) / \mathrm{P}_{1}(3)$ ratio with the average weighted temperature, the magnitude of the contamination under $\mathrm{P}_{1}(3)$ is $1.1 \%$ (cf. $1.8 \%$ for the principal data set). The conclusions drawn from the principal data set are consistent with the expanded data set.

Table 4. Average temperatures and uncertainty estimates for individual ratios and the weighted temperature (see text) for the expanded data set (see text, 277 spectra): (A) average temperatures; (B) standard deviation; (C) standard error in the mean; (D) average 'counting' error for individual spectra; (E) average auroral correction; (F) average error in individual spectra; (G) estimated error in average temperatures.

\begin{tabular}{lcccrrrr}
\hline & $\mathrm{A}$ & $\mathrm{B}$ & $\mathrm{C}$ & $\mathrm{D}$ & $\mathrm{E}$ & $\mathrm{F}$ & $\mathrm{G}$ \\
\hline $\mathrm{P}_{1}(2) / \mathrm{P}_{1}(3)$ & $227 \mathrm{~K}$ & $20 \mathrm{~K}$ & $1 \mathrm{~K}$ & $14 \mathrm{~K}$ & $-1 \mathrm{~K}$ & $18 \mathrm{~K}$ & $3 \mathrm{~K}$ \\
$\mathrm{P}_{1}(2) / \mathrm{P}_{1}(4)$ & $222 \mathrm{~K}$ & $13 \mathrm{~K}$ & $1 \mathrm{~K}$ & $6 \mathrm{~K}$ & $-1 \mathrm{~K}$ & $10 \mathrm{~K}$ & $2 \mathrm{~K}$ \\
$\mathrm{P}_{1}(2) / \mathrm{P}_{1}(5)$ & $221 \mathrm{~K}$ & $11 \mathrm{~K}$ & $1 \mathrm{~K}$ & $5 \mathrm{~K}$ & $-3 \mathrm{~K}$ & $8 \mathrm{~K}$ & $2 \mathrm{~K}$ \\
$\mathrm{P}_{1}(3) / \mathrm{P}_{1}(4)$ & $220 \mathrm{~K}$ & $14 \mathrm{~K}$ & $1 \mathrm{~K}$ & $9 \mathrm{~K}$ & $-1 \mathrm{~K}$ & $13 \mathrm{~K}$ & $2 \mathrm{~K}$ \\
$\mathrm{P}_{1}(3) / \mathrm{P}_{1}(5)$ & $220 \mathrm{~K}$ & $11 \mathrm{~K}$ & $1 \mathrm{~K}$ & $6 \mathrm{~K}$ & $-4 \mathrm{~K}$ & $10 \mathrm{~K}$ & $3 \mathrm{~K}$ \\
$\mathrm{P}_{1}(4) / \mathrm{P}_{1}(5)$ & $220 \mathrm{~K}$ & $14 \mathrm{~K}$ & $1 \mathrm{~K}$ & $11 \mathrm{~K}$ & $-7 \mathrm{~K}$ & $14 \mathrm{~K}$ & $4 \mathrm{~K}$ \\
wtd. average & $221 \mathrm{~K}$ & $11 \mathrm{~K}$ & $1 \mathrm{~K}$ & $4 \mathrm{~K}$ & $-3 \mathrm{~K}$ & $8 \mathrm{~K}$ & $2 \mathrm{~K}$ \\
\hline
\end{tabular}


Figure 4 shows the seasonal variation of the weighted temperatures of the spectra in the expanded data set. Errors plotted are the maximum of the weighted standard deviation and the weighted average counting error. Generally, the weighted standard deviation is larger, but as this value may be fortuitously low, we have set the weighted counting error as a minimum error. Significant variability is seen in the data, as would be expected from wave and tidal activity. This variability is larger in the three mid-winter observing campaigns.

Also plotted in Fig. 4 are CIRA 1986 model temperatures for $70^{\circ} \mathrm{S}$ and altitudes $86.3 \mathrm{~km}$ and $87.7 \mathrm{~km}$ (Fleming et al., 1990). OH rotational temperatures from Davis are consistent with reported northernhemisphere polar observations of an extended, warm, upper-mesosphere/mesopause winter period (Lübken and von Zahn, 1991). This is not reflected in the CIRA 1986 model (Lübken and von Zahn, 1991). The Davis data presented are almost all confined to the winter period, although the first and last campaigns show some decrease in temperature. The mean of the weighted temperatures for the whole of the extended data set is $221 \pm 2 \mathrm{~K}$. Means for each new moon campaign period are given in Table 5.

Given the uncertainty in the published $\mathrm{OH}(6-2)$ transition probabilities (cf. Turnbull and Lowe, 1989; our Table 2) which can yield temperatures up to $12 \mathrm{~K}$ lower than those listed here, the Davis winter temperatures are not inconsistent with the CIRA model midwinter value of $222 \mathrm{~K}$. For comparison, the Davis 1990 winter average temperature of $224 \pm 2 \mathrm{~K}$ [for months May, June and July (MJJ), a total of 160 spectra] is higher than the $86-\mathrm{km}$ average temperature of $210 \mathrm{~K}$, for the equivalent northern-hemisphere months of November, December and January (NDJ) from lidar and a variety of rocket techniques reported

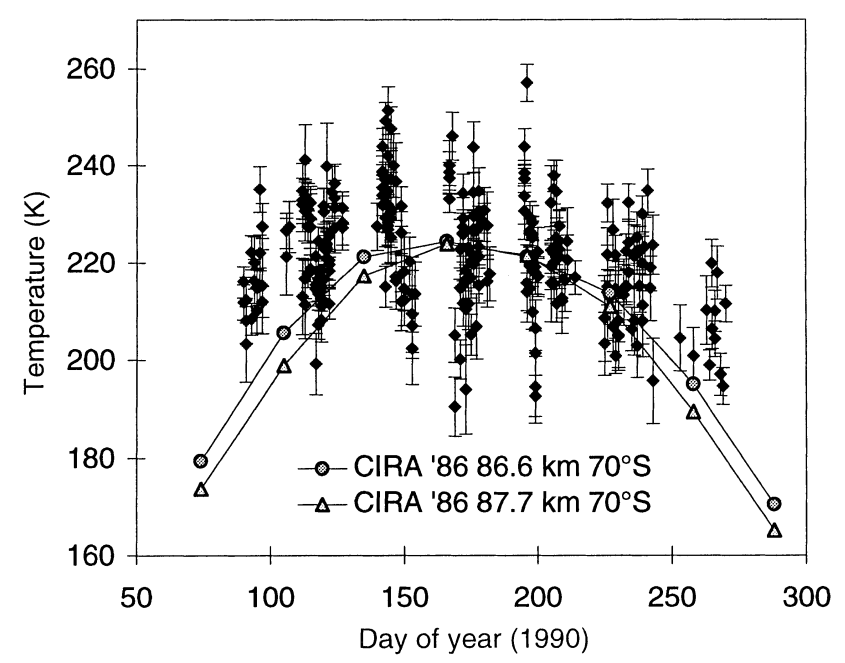

Fig. 4. Seasonal temperature variation for the extended data set (see text) collected during 1990. Temperatures plotted are weighted temperatures for each of the 277 spectra. Error bars indicate the maximum of the weighted standard deviation and the weighted counting error (see text for definitions). CIRA model values are shown for 86.6 and $87.7 \mathrm{~km}$ and $70^{\circ} \mathrm{S}$.
Table 5. The duration of each campaign, number of spectra (n), mean temperature and standard error in the mean.

\begin{tabular}{clll}
\hline DOY & $n$ & $\bar{T}(\mathrm{~K})$ & std. error $(\mathrm{K})$ \\
\hline $90-97$ & 18 & 216 & 2 \\
$106-127$ & 60 & 223 & 1 \\
$140-154$ & 41 & 228 & 2 \\
$167-182$ & 49 & 222 & 2 \\
$195-214$ & 53 & 222 & 2 \\
$225-243$ & 44 & 216 & 1 \\
$253-270$ & 12 & 206 & 2 \\
\hline
\end{tabular}

by Lübken and von Zahn (1991). NDJ averages of OH rotational temperature from Offermann and Gerndt (1990) for Oslo $\left(60^{\circ} \mathrm{N}\right) 217 \mathrm{~K}$, and Myrabo (1986) for Longyearbyen $\left(78^{\circ} \mathrm{N}\right)$ of $214 \mathrm{~K}$, use Mies (1974) transition probabilities. For comparison, Davis MJJ temperatures using Mies transistion probabilities are $217 \pm 2 \mathrm{~K}$. Although these results are similar, comparisons between years are difficult because of reported positive correlations between mesospheric temperatures and solar activity (Lübken and von Zahn, 1991; Labitzke and Chanin, 1988; Sahai et al., 1996) of at least $20 \mathrm{~K}$ between solar maximum and minimum. 1990 was a year of high solar activity, while the Longyearbyen average (Myrabo, 1986) comes from four winters, 1980-1985, which include years of low solar activity.

Williams (1996) reports 1987 Davis winter average temperatures, using the $\mathrm{OH}(8-3)$ emission, of $205 \pm 5 \mathrm{~K}$. This was obtained using Langhoff transition probabilities and no instrument response corrections were made. We are reanalysing this data set.

An attempt was made to determine a diurnal temperature variation. Temperatures were plotted against time and solar zenith angle, for the principal and expanded data sets, and for two- to three-week newmoon campaign intervals. None of these plots, over the strictly limited hours of observations in dark skies, revealed any significant diurnal temperature variation. We have not tried to extract tidal, planetary or gravitywave periodicities from these data.

The summed relative intensity estimates of (6-2) $\mathrm{P}_{1}(2), \mathrm{P}_{1}(3), \mathrm{P}_{1}(4)$ and $\mathrm{P}_{1}(5)$ lines are plotted against day of year in Fig. 5 and against hours (UT) in Fig. 6. Only data from the principal data set are plotted. The sum of the $\mathrm{P}_{1}(2), \mathrm{P}_{1}(3), \mathrm{P}_{1}(4)$ and $\mathrm{P}_{1}(5)$ lines is $33 \%$ of the whole (6-2) band, for temperatures in the range 215 $230 \mathrm{~K}$. As for the temperature measurements, large variability is seen particularly in mid-to-late winter, suggestive of strong wave activity. Although the variability makes trend determinations difficult, there is a suggestion in Fig. 6. of a trend towards lower intensities through the night. In Fig. 5 there is a suggestion of a mid-winter minimum in intensity, with peaks in intensity occuring near the equinoxes. This is similar to the trend predicted by Le Texier et al. (1987), for the OH(5-3) band at high latitudes. 


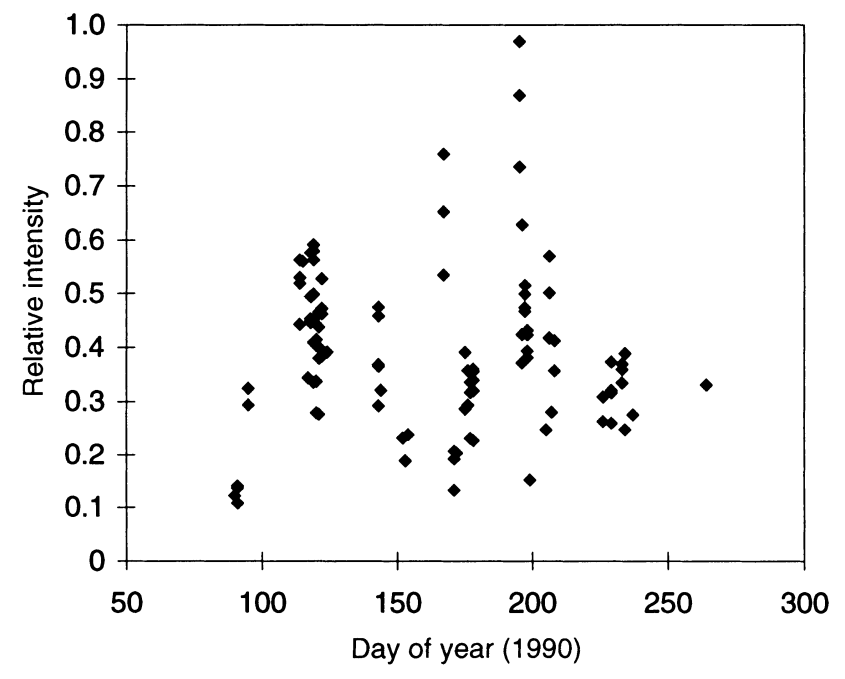

Fig. 5. Seasonal $\mathrm{OH}(6-2)$ emission intensity variation for the principal data set (solar altitude $<-18^{\circ}$, lunar altitude $<0^{\circ}$, no cloud, OI $<\mathrm{P}_{1}(3), 104$ spectra) as a function of day of year, 1990.

\section{Discussion}

We have looked in detail at deriving temperatures from the $\mathrm{OH}(6-2)$ band and have noted a number of weak spectral features in the vicinity of the $\mathrm{P}_{1}$-branch lines which, if not correctly allowed for, will influence derived temperatures. The resolution of our spectra and the technique of summing only over $0.25 \mathrm{~nm}$ centred on the line peaks, enables us to reduce the allowance necessary for $\mathrm{Q}_{1}(5)$ contamination of the $\mathrm{P}_{1}(2)$ line. Not all of both components of the $\Lambda$-doubled $\mathrm{Q}_{1}(5)$ line fall inside our $\mathrm{P}_{1}(2)$ spectral interval. Lower-resolution spectrometers, filter photometers and $\mathrm{OH}$ imaging systems will not be able to avoid most of the influence of the entire

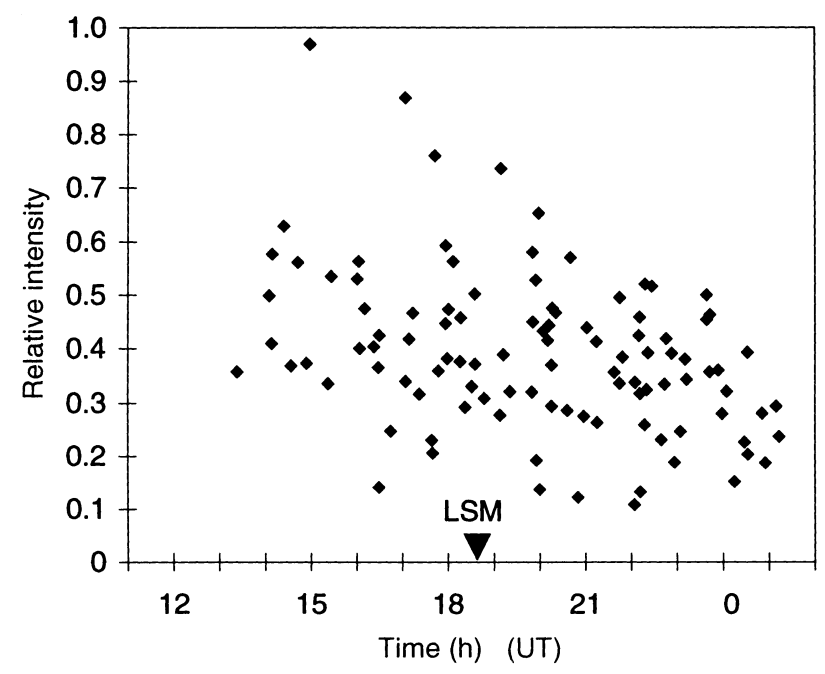

Fig. 6. $\mathrm{OH}(6-2)$ emission intensity variation for the principal data set (solar altitude $<-18^{\circ}$, lunar altitude $<0^{\circ}$, no cloud, OI $<\mathrm{P}_{1}(3), 104$ spectra) plotted as a function of time. The solid arrow indicates local solar midnight.
$Q_{1}(5)$ emission on the $P_{1}(2)$ line. For such instruments, not allowing for the $\mathrm{Q}_{1}(5)$ influence will reduce the $\mathrm{P}_{1}(2) / \mathrm{P}_{1}(3)$ ratio temperature by some $10 \mathrm{~K}, \mathrm{P}_{1}(2) /$ $\mathrm{P}_{1}(4)$ by $4 \mathrm{~K}$ and $\mathrm{P}_{1}(2) / \mathrm{P}_{1}(5)$ by $3 \mathrm{~K}$, for a rotational temperature of the order of $220 \mathrm{~K}$.

The centre of the $\mathrm{Q}_{1}(6)$ line is some $0.70 \mathrm{~nm}$ below the $\mathrm{P}_{1}(3)$ line, but its large $\Lambda$-doubling of $0.19 \mathrm{~nm}$ needs to be considered. It is also important to avoid the regions of these features for background determinations. If all the identified features in the vicinity of the $\mathrm{P}_{1}(3)$ line were incorporated in the intensity of this line, considerable error may result. At $220 \mathrm{~K}$ the $\mathrm{P}_{1}(3)$ intensity would be overestimated by some $7 \%$, including an estimated average contribution from $\mathrm{OH}(5-1) \mathrm{P}_{1}(12)$ of $1.5 \%$, resulting in an increase in the $\mathrm{P}_{1}(2) / \mathrm{P}_{1}(3)$ derived temperature by $41 \mathrm{~K}$, and a reduction in the $\mathrm{P}_{1}(3) / \mathrm{P}_{1}(4)$ and $\mathrm{P}_{1}(3) / \mathrm{P}_{1}(5)$ temperatures by some 22 and $10 \mathrm{~K}$, respectively. $\mathrm{Q}_{1}(5)$ on $\mathrm{P}_{1}(2)$ and $\mathrm{Q}_{1}(6)$,

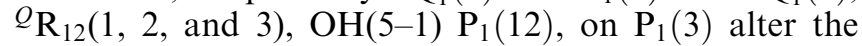
$\mathrm{P}_{1}(2) / \mathrm{P}_{1}(3)$ ratio in opposite senses, but in combination they result in a $2 \mathrm{~K}$ increase. The unthermalized $\mathrm{OH}(5-$ 1) $P_{1}(12)$ contamination makes the $\mathrm{OH}(6-2) \mathrm{P}_{1}(3)$ line unsuitable for absolute temperature measurements.

Average temperatures of the $\mathrm{P}_{1}(5)$ ratios provide evidence that this line is thermalized. We have no evidence that the $\mathrm{Q}_{1}(5)$ is not thermalized, but we measure $\mathrm{Q}_{1}(6)$ significantly brighter $(5 \pm 1$ times $)$ than its theoretical thermalised intensity.

Uncertainty in the appropriate transition probabilities does not preclude determination of climate change if consistent values are used. Excluding this source of error, the Davis spectra from 1990, which are accumulated over a $1 \mathrm{~h}$ interval, yield an average temperature uncertainty of $8 \mathrm{~K}$ (Table 3 , column $\mathrm{H}$ ). Most of this uncertainty is attributable to the non-simultaneous observations of the lines. This is avoided in Fourier transform instruments (e.g. Steed and Baker, 1979), or in CCD or photographic grating instruments. There is considerable scope for improving the time resolution/ accuracy of $\mathrm{OH}(6-2)$ rotational temperatures obtained from measurements with our CZT spectrometer. By concentrating on one ratio and associated background and auroral measurements, an acquisition time near the Brunt-Väisälä period is possible.

Auroral influences can be significant and can generally be allowed for. It is, however, necessary to monitor an $\mathrm{N}_{2}$ emission, rather than the brighter OI emission, for corrections to be made to temperature measurements.

The most significant uncertainty in average temperature determinations which is difficult to reduce is the instrumental response calibration. For the Davis spectra from 1990 this amounts to about $2 \mathrm{~K}$ (Table 3, column $\mathrm{G})$. More calibrations and attention to temperature stability of the GaAs photomultiplier tube may reduce this uncertainty, but it will remain significant.

Solar cycle, seasonal, diurnal, tidal and planetaryscale variations must also be accounted for in seeking climate-change variations. These variations will be discussed when a larger data set is analysed. 


\section{Conclusions}

A Czerny-Turner scanning spectrometer has been used for detailed observations of the $\mathrm{OH}(6-2)$ Meinel band emissions with the intention of establishing a data base for monitoring climate change in the Antarctic upper mesosphere. Weak spectral features identified include minor $\mathrm{OH}$ emission lines and auroral features. For the $\mathrm{OH}(6-2)$ band:

the $\mathrm{Q}_{1}(5)$ line is coincident with the $\mathrm{P}_{1}(2)$ line; the $\mathrm{Q}_{1}(6)$, satellite lines ${ }^{Q} \mathrm{R}_{12}(1,2$, and 3), and $\mathrm{OH}(5-1) \mathrm{P}_{1,2}(12)$ are within $\pm 1 \mathrm{~nm}$ of the $\mathrm{P}_{1}(3)$ line; the satellite line ${ }^{P} \mathrm{Q}_{12}(2)$ is within $1 \mathrm{~nm}$ of the $\mathrm{P}_{1}(4)$ line; and

$\mathrm{P}_{1}(2) / \mathrm{P}_{1}(4)$ is the most favourable ratio, for temperatures near $220 \mathrm{~K}$ in the auroral region.

From OH(6-2) observations at Davis in 1990, the average of the weighted temperatures from three possible ratios from three lines in the band was $221 \pm 2 \mathrm{~K}$, using Turnbull and Lowe (1989) transition probabilities. The mid-winter average temperature is consistent with the 1986 CIRA mid-winter temperature, but this result is dependent on the choice of transition probabilities.

Acknowledgements. Computer models of auroral spectra utilized for identifying and allowing for auroral contamination of the $\mathrm{OH}(6-2)$ band features were kindly provided by R.L. Gattinger, NRC, Ottawa, Canada. This project has been supported by the Australian Antarctic Science Advisory Committee. P.A. Greet was supported by an Australian Research Council postdoctoral fellowship, jointly sponsored by the Institute of Antarctic and Southern Ocean Studies, University of Tasmania and the Australian Antarctic Division. A.R. Klekociuk assisted with advice on possible contaminating emissions and generation of theoretical auroral spectra. We are grateful to D.E. Osterbrock and J. Fulbright (University of California) for identification of the $\mathrm{OH}(5-1)$ features and useful discussions of their high-resolution spectra. Comments from two referees permitted considerable progress in our work presented here.

Topical Editor F. Vial thanks P. Espy and J. Scheer for their help in evaluating this paper.

\section{References}

Armstrong, E. B., The influence of a gravity wave on the airglow hydroxyl rotational temperature at night, J. Atmos. Terr. Phys., 37, 1585-1591, 1975.

Armstrong, E. B., The association of visible airglow features with a gravity wave, J. Atmos. Terr. Phys., 44, 325-336, 1982.

Baker, D. J. and A. T. Stair, Rocket measurements of the altitude distributions of the hydroxyl airglow, Phys. Scr., 37, 611-622, 1988.

Balsley, B. B., R. F. Woodman, M. Sarango, R. Rodriguez, J. Urbina, E. Ragaini, J. Carey, M. Huaman, and A. Giraldez, On the lack of southern hemisphere polar mesosphere summer echoes, J. Geophys. Res., 100, 11685-11693, 1995.

Bills, R. E., C. S. Gardner, and S. J. Franke, Na Doppler/ Temperature Lidar: Initial mesopause region observations and comparison with the Urbana medium frequency radar, J. Geophys. Res., 96, 22701-22707, 1991.

Cogger, L. L., R. D. Elphinstone, and D. H. Giers, Wave characteristics obtained from $\mathrm{OH}$ rotational temperatures and $557.7 \mathrm{~nm}$ airglow intensities, J. Atmos. Terr. Phys., 50, 943-949, 1988.
Coxon, J. A., Optimum molecular constants and term values for the $\mathrm{X}^{2} \Pi(v \leq 5)$ and $\mathrm{A}^{2} \Sigma^{+}(v \leq 3)$ states of $\mathrm{OH}$, Can. J. Phys., 58, 933-949, 1980.

Coxon, J. A., and S. C. Foster, Rotational analysis of hydroxyl vibration-rotation emission bands: Molecular constants for $\mathrm{OH}$ $\mathrm{X}^{2} \Pi, 6 \leq v \leq 10$, Can. J. Phys., 60, 41-48, 1982.

Elphinstone, R. D., L. L. Cogger, J. S. Murphree, G. S. N. Murty, and J. W. Meriwether, The analysis of hydroxyl rotational temperatures to characterize moving thermal structures near the mesopause, J. Atmos. Terr. Phys., 50, 657-669, 1988.

Fleming, E. L., S. Chandra, J. J. Barnett, and M. Corney, Zonal mean temperature, pressure, zonal wind, and geopotential height as functions of latitude, Adv. Space. Res., 10(12), 1159, 1990.

Greet, P. A., Mesospheric observations by high-resolution FabryPerot spectrometers: calibrations required for climate change studies, J. Atmos. Terr. Phys., 59, 281-294, 1997.

Goldman, A., Line parameters for the atmospheric band system of OH, Appl. Opt., 21, 2100-2102, 1982.

Hecht, J. H., R. L. Walterscheid, G. G. Sivjee, A. B. Christensen, and J. B. Pranke, Observations of wave-driven fluctuations of $\mathrm{OH}$ nightglow emission from Sondre Stromfjord, Greenland, J. Geophys. Res., 92, 6091-6099, 1987.

Hobbs, B. G., I. M. Reid, and P. A. Greet, Mesospheric rotational temperatures determined from the $\mathrm{OH}(6-2)$ emission above Adelaide, Australia, J. Atmos. Terr. Phys., 58, 1337-1344, 1996.

Keckhut, P., A. Hauchecorne, and M. L. Chanin, Midlatitude longterm variability of the middle atmosphere: trends and cyclic and episodic changes, J. Geophys. Res., 100, 18887-18897, 1995.

Labitzke, K., and M.-L. Chanin, Changes in the middle atmosphere in winter related to the 11-year solar cycle, Ann. Geophysicae, 6, 643-644, 1988.

Langhoff, S. R., H.-J. Werner, and P. Rosmus, Theoretical transition probabilities for the $\mathrm{OH}$ Meinel system, J. Mol. Spectr., 118, 507-529, 1986.

Le Texier, H., S. Solomon, and R. R. Garcia, Seasonal variability of the OH Meinel bands, Planet. Space. Sci., 35, 977-989, 1987.

Longhurst, R. S., Geometrical and physical optics, Longmans, London, 1957.

Lowe, R. P., K. L. Gilbert, and D. N. Turnbull, High-latitude summer observations of the hydroxyl airglow, Planet. Space Sci., 39, 1263-1270, 1991.

Lowe, R. P., L. M. LeBlane, and K. L. Gilbert, WINDII/UARS observation of twilight behaviour of the hydroxyl airglow, at mid-latitude equinox, J. Atmos. Terr. Phys., 58, 1863-1869, 1996.

Lübken, F.-J. and U. von Zahn, Simultaneous temperature measurements in the mesosphere and lower thermosphere during MAC/EPSILON campaign, Planet. Space Sci., 89, 1303-1314, 1989.

Lübken, F.-J. and U. von Zahn, Thermal structure of the mesopause region at polar latitudes, J. Geophys. Res. 96, 20841-20857, 1991

Lübken, F.-J., K.-H. Fricke, and M. Langer, Noctilucent clouds and the thermal structure near the Artic mesopause in summer, J. Geophys. Res., 101, 9489-9508, 1996.

Meriwether, J. W., Ground-based measurements of mesospheric temperatures by optical means, in Middle atmosphere program handbook for MAP, Ed. R. Vincent 13, pp 19-40, 1985.

Mies, F. H., Calculated vibrational transition probabilities of $\mathrm{OH}\left(\mathrm{X}^{2} \Pi\right)$, J. Mol. Spectrosc., 53, 150-180, 1974.

Morris, R. J., D. P. Monselesan, and A. R. Klekociuk, Australian Antarctic middle and upper atmosphere physics - A new direction, Adv. Space Res., 16(5), 151-162, 1995.

Myrabo, H. K., Temperature variation at mesopause levels during winter solstice at $78^{\circ} \mathrm{N}$, Planet-Space Sci., 32, 249255, 1984

Myrabo, H. K., Winter-season mesopause and lower thermosphere temperatures in the northern polar region, Planet Space Sci., 34, 1023-1029, 1986. 
Myrabo, H. K., and O. E. Harang, Temperatures and tides in the high-latitude mesopause region as observed in the $\mathrm{OH}$ night airglow emissions, J. Atmos. Terr. Phys., 50, 739-748, 1988.

Myrabo, H. K., C. S. Deehr, R. Viereck, and K. Henriksen, Polar mesopause gravity wave activity in the sodium and hydroxyl night airglow, J. Geophys. Res., 92, 2527-2534, 1987.

Offermann, D., R. Gerndt, and R. Küchler, Middle-atmosphere temperature measurements as compared to atmospheric models, Adv. Space Res., 7(10), 97-104, 1987.

Offermann, D., and R. Gerndt, Upper-mesosphere temperatures from $\mathrm{OH}^{*}$ emissions, Adv. Space Res., 10(12), 217-221, 1990.

Olivero, J. J., and G. E. Thomas, Climatology of polar mesospheric clouds, J. Atmos. Sci., 43, 1263-1274, 1986.

Osterbrock, D. E., J. P. Fulbright, and T. A. Bida, Night-sky highresolution spectral atlas of $\mathrm{OH}$ emission lines for Echelle spectrograph wave-length calibration. II, Publ. Astron Soc. Pac., 109, 614-627, 1997.

Pendleton, W. R., P. J. Espy, and M. R. Hammond, Evidence for non-local-thermodynamic-equilibrium rotation in the $\mathrm{OH}$ nightglow, G. Geophys. Res., 98, 11567-11579, 1993.

Rothman, L., R. Gamache, R. Tipping, C. Rinsland, M. Smith, D. Benne, V. Malathy Devi, J. M. Flaud, C. Camy-Peyret, A. Perrin, A. Goldman, S. Massie, L. Brown, and R. Toth, The HITRAN molecular database: Editions of 1991 and 1992, J. Quant. Spectrosc. Radiat. Transfer, 48, 469-507, 1992.

Sahai, Y., D. H. Giers, L. L. Cogger, P. R. Fagundes, and G. P. Garbe, Solar flux and seasonal variations of the mesopause temperatures at $51^{\circ} \mathrm{N}$, J. Atmos. Terr. Phys. 58, 1927-1934, 1996.

Scheer, J., What can be learned from rotational temperatures derived from ground-based airglow observations about the aeronomy of the southern hemisphere, Adv. Space Res., 16(5), 61-69, 1995.

Scheer, J., and E. R. Reisin, Rotational temperatures for $\mathrm{OH}$ and $\mathrm{O}_{2}$ airglow bands measured simultaneously from El Leoncito, (31 ${ }^{\circ} 48^{\prime}$ S). J. Atmos. Terr. Phys., 52, 47-57, 1990.

Sivjee, G. G., Airglow hydroxyl emissions, Planet. Space Sci., 40, 235-242, 1992.
Sivjee, G. G., and R. M. Hamwey, Temperature and chemistry of the polar mesopause OH, J. Geophys. Res., 92, 4663-4672, 1987.

Sivjee, G. G., and R. L. Walterscheid, Six-hour zonally symmetric tidal oscillations of the winter mesopause over the South Pole station, Planet Space Sci., 42, 447-453, 1994.

Steed, A. J., and D. J. Baker, Night-sky spectral emission measurements $(\lambda 0.9-2.3 \mu \mathrm{m})$ using a field-widened interferometer-spectrometer, Appl. Opt. 18, 3386-3389, 1979.

Stubbs, L. C., J. S. Boyd, and F. R. Bond, Measurement of the $\mathrm{OH}$ rotational temperature at Mawson, East Antarctica, Planet. Space Sci., 31, 923-932, 1983.

Takahashi, H., Y. Sahai, and P. P. Batista, Tidal and solar cycle effects on the OI $5577 \AA, \mathrm{NaD}$ and $\mathrm{OH}(8,3)$ airglow emissions observed at $23^{\circ} \mathrm{S}$, Planet Space. Sci., 32, 897-902, 1984.

Takahashi, H., Y. Sahai, and P. P. Batista, Airglow $\mathrm{O}_{2}\left({ }^{1} \Sigma\right)$ atmospheric band at $8645 \AA$ and the rotational temperature observed at $23^{\circ}$ S, Planet. Space Sci., 34, 301-306, 1986.

Taylor, M. J., R. P. Lowe, and D. J. Baker, Hydroxyl temperature and intensity measurements during noctilucent cloud displays, Ann. Geophysicae, 13, 1107-1116, 1995.

Thomas, G. E., Global change in the mesosphere-lower thermosphere region: Has it already arrived? J. Atmos. Terr. Phys., 58, 1629-1656, 1996.

Turnbull, D. N., and R. P. Lowe, Vibrational population distribution in the hydroxyl night airglow, Can. J. Phys. 61, 244-250, 1983.

Turnbull, D. N., and R. P. Lowe, New hydroxyl transition probabilities and their importance in airglow studies, Planet. Space Sci., 37, 723-738, 1989.

Viereck, R. A., and C. S. Deehr, On the interaction between gravity waves and $\mathrm{OH}$ Meinel (6-2) and the $\mathrm{O}_{2}$ Atmospheric (0-1) bands in the polar night airglow, J. Geophys. Res., 94, 53975402, 1989.

Williams P. F. B., OH rotational temperatures at Davis, Antarctica, via scanning spectrometer, J. Geophys. Res., 44, 163-170, 1996. 